Primary Care Practitioners' Response to 2019 Novel Coronavirus Outbreak in China

Zhijie Xu, M.B.B.S

Yi Qian, MD

Lizheng Fang, MD

Mi Yao, MD

Author Affiliations: Department of General Practice, Sir Run Run Shaw hospital, Zhejiang University School of Medicine, Hangzhou, Zhejiang Province, China (Xu, Qian, Fang); Department of General Practice, Peking University Health Science Center, Beijing, China (Yao); Institute of Applied Health Research, University of Birmingham, Birmingham, UK (Yao)

Corresponding Author: Mi Yao, MD, Institute of Applied Health Research, University of Birmingham, Edgbaston Birmingham, B15 2TT, UK (Email: MXY768@student.bham.ac.uk; Tel: 44 7550279618).

Word count : 583 


\section{Primary Care Practitioners' Response to 2019 Novel Coronavirus Outbreak in China}

The emerging outbreak of the 2019 novel coronavirus (2019-nCoV) originated from Wuhan poses a great challenge to healthcare system in China. ${ }^{1}$ Primary care practitioners (PCPS) have an important role in district communicable disease control. ${ }^{2}$ However, because primary health-care system in China still needs to be substantially strengthened, ${ }^{3,4}$ whether PCPS are proactive and capable in responding to the outbreak remains unclear. Using an electronic questionnaire, we surveyed a national sample of PCPs to assess their response to novel coronavirus outbreak.

Methods From Jan 28, 2020 to Feb 3, 2020, we invited a national random sample of PCPs in China to participate in an online survey through social media. The questionnaire was adapted from The Notice of Improving Prevention of 2019-nCoV causing Pneumonia in Primary Care Settings issued by China's National Health Commission on Jan 27, 2020. ${ }^{5}$ It included 6 questions of demographic information, duration and scope of clinical practice as well as types of practice settings, and 8 statements regarding whether the PCPs were making efforts to respond to novel coronavirus outbreak in daily practice.

Eligible PCPs participated in this survey voluntarily and were not compensated. Once completed and returned, the survey was regarded as informed consent by participants. This study was deemed exempt from review by the Sir Run Run Shaw 
Hospital Ethics Committee.

One of the authors (Z. X.) reviewed the returned questionnaires and excluded the unqualified data. All statistical analyses were performed with Stata version 15.0 and a two-sided $P<.05$ were considered statistically significant.

Results Among 1751 respondents (response rate: 62\%), 784 (45\%) were men and 1135 (65\%) were family physicians. The mean (SD) age of respondents was 38(8) years, and the duration of practice was 15 (9) years (Table 1). Most of PCPs were proactive in studying knowledge and skills of containing 2019-nCoV (99\%, n=1741), teaching their consulting patients ways of prevention (94\%, $n=1650$ ), and comforting the worried patients $(86 \%, n=1509)$. The study also showed that $69 \%(n=1221)$ of PCPS used online consultation for health education. However, less than half $(48 \%$, $\mathrm{n}=849$ ) reported to transfer the suspected infected patients to hospitals for further diagnosis and treatment. The rates of visiting, transferring and monitoring the suspected cases varied among PCPs in different practice settings, geographic regions, and specialties, respectively (Table 2).

Discussion We found that most of China's PCPs attached great importance to the national epidemic outbreak and had some preparation of knowledge and skills for the emerging situation. They took multiple control measures instructed by health authorities, and the majority spontaneously provide online consultation to local community, which effectively increased the coverage of health services during a 
pandemic period and strengthened the relationship between PCPS and the public. Nevertheless, the capacity of transferring suspected cases remained relatively inadequate. Hence, China's hierarchical medical system for managing communicable disease remains to be improved.

The result that PCPs' responses varied among practitioners, regions and settings may be attributed to the uneven distribution of healthcare providers and resources across the country. It indicates that policies for containing the coronavirus outbreak in primary care should consider different challenges PCPs encounter and adjust measures to individual conditions.

Our study includes several limitations. First, there is a diversity of control measures among districts and PCPs' response may be affected by local authorities. Second, PCPs other than clinicians are not included in our study because they are not responsible for screening and transfer.

Policy-makers should take steps to improve PCPs' capacity and consciousness to ready for rapid response, and strengthen collaboration between PCPS and specialists in hospitals.

Author Contributions: Dr Yao had full access to all the data in the study and takes responsibility for the integrity of the data and the accuracy of the data analysis.

Concept and design: Xu.

Acquisition, analysis, or interpretation of data: All authors.

Drafting of the manuscript: Xu, Yao, Qian. 
Critical revision of the manuscript for important intellectual content: All authors.

Supervision: Fang.

Conflict of Interest Disclosures: None reported.

Funding/Support: None reported.

1. Paules $\mathrm{Cl}$, Marston HD, Fauci AS. Coronavirus Infections-More Than Just the Common Cold [published online January 23, 2020]. JAMA. doi:10.1001/jama.2020.0757.

2. Harapan H, Rajamoorthy Y, Utomo PS, et al. Knowledge and attitude towards pregnancy-related issues of Zika virus infection among general practitioners in Indonesia. BMC Infect Dis. 2019; 19:693-704. doi: 10.1016/j.cegh.2018.12.006.

3. Yuan B, Balabanova D, Gao J, et al. Strengthening public health services to achieve universal health coverage in China. BMJ. 2019;365:I2358. doi:10.1136/bmj.I2358.

4. Li X, Lu J, Hu S, et al. The primary health-care system in China. Lancet. 2017; 390(10112):2584-2594. doi: 10.1016/S0140-6736(17)33109-4.

5. National Health Commission of the People's Republic of China. The Notice of Improving Prevention of 2019-nCoV causing Pneumonia in Primary Care Settings. http://www.xjhfpc.gov.cn/info/2072/17376.htm. Accessed Jan 29, 2020.

6. China's National Bureau of Statistics. Division of eastern, western, central and northeastern China.

http://www.stats.gov.cn/ztjc/zthd/sjtjr/dejtjkfr/tjkp/201106/t20110613_71947.htm. Accessed Jan 29, 2020. 
Table1. Characteristics of Respondents

\begin{tabular}{|l|c|}
\hline Characteristics & $\begin{array}{c}\text { Finding } \\
\text { (N=1751) }\end{array}$ \\
\hline Age, mean (SD), y & $38(8)$ \\
\hline Male sex, No.(\%) & $784(45)$ \\
\hline Years of practice, $y$ & $15(9)$ \\
\hline Region, ${ }^{\text {a }}$ No.(\%) & $217(12)$ \\
\hline Northeast & $256(15)$ \\
\hline Center & $653(37)$ \\
\hline East & $625(36)$ \\
\hline West & \\
\hline Practice setting, No.(\%) & $913(52)$ \\
\hline Community health center & $630(36)$ \\
\hline Township health center & $65(4)$ \\
\hline Private clinic & $143(8)$ \\
\hline Village clinic & \\
\hline Specialty, No.(\%) & $1135(65)$ \\
\hline Family medicine & $286(16)$ \\
\hline Internal medicine & $57(3)$ \\
\hline Surgery & $110(6)$ \\
\hline Traditional Chinese medicine & $163(9)$ \\
\hline Others ${ }^{b}$ & \\
\hline
\end{tabular}

${ }^{a}$ The division is based on regional socioeconomic status issued by China's National Bureau of Statistics. ${ }^{6}$

${ }^{b}$ Other clinical types include preventive medicine, rehabilitation and stomatology. 
Table2. PCPs' response to 2019 novel coronavirus outbreak

\begin{tabular}{|l|c|c|}
\hline Statement & $\begin{array}{c}\text { Yes, } \\
\text { No. (\%; 95\%Cl) }\end{array}$ & $\begin{array}{c}\text { No, } \\
\text { No. (\%; 95\%Cl) }\end{array}$ \\
\hline $\begin{array}{l}\text { I have studied clinical practice guidelines on } \\
\text { containing novel coronavirus outbreak }\end{array}$ & $1741(99 ; 99-100)$ & $10(1 ; 0-1)$ \\
\hline $\begin{array}{l}\text { I have participated in primary screening } \\
\text { suspected cases in daily practice }\end{array}$ & $1383(79 ; 77-81)$ & $368(21 ; 19-23)$ \\
\hline $\begin{array}{l}\text { I have visited residents and/or villagers to } \\
\text { screen suspected cases }\end{array}$ & $1002(57 ; 55-60)$ & $749(43 ; 40-45)$ \\
\hline $\begin{array}{l}\text { I have taught the consulting patients how to } \\
\text { prevent infection of 2019 novel coronavirus }\end{array}$ & $1650(94 ; 93-95)$ & $101(6 ; 5-7)$ \\
\hline $\begin{array}{l}\text { I have transferred the suspected cases to } \\
\text { hospitals for further diagnosis and treatment }\end{array}$ & $849(48 ; 46-51)$ & $902(52 ; 49-54)$ \\
\hline $\begin{array}{l}\text { I have follow up and monitored health } \\
\text { conditions of the suspected cases }\end{array}$ & $1027(59 ; 56-61)$ & $724(41 ; 39-44)$ \\
\hline $\begin{array}{l}\text { I have comforted the consulting patients if } \\
\text { they are worried or panic }\end{array}$ & $1509(86 ; 85-88)$ & $242(14 ; 12-15)$ \\
\hline $\begin{array}{l}\text { I have provided consultation to residents } \\
\text { and/or villagers through the Internet (e.g., } \\
\text { WeChat) }\end{array}$ & $1221(70 ; 68-72)$ & $530(30 ; 28-32)$ \\
\hline
\end{tabular}

${ }^{a}$ PCPs in village clinics $(68 \%, n=97)$ were more proactive in home visit than PCPs in other settings (community health center: $59 \%, n=541$; township health center: $55 \%$, $\mathrm{n}=346$; private clinic: $28 \%, \mathrm{n}=18)(\mathrm{P}=0.000)$.

${ }^{\mathrm{b}}$ Transfer were more common among PCPs in central China $(58 \%, \mathrm{n}=149)$ than PCPs in other regions (east: $51 \%, n=335$; west: $47 \%, n=295$; northeast: $32 \%$, $\mathrm{n}=70)(\mathrm{P}=.001)$

${ }^{\mathrm{c}} 62 \%$ ( $n=706$ ) of PCPs of family medicine followed up and monitored health conditions of the suspected cases, compared with $52 \%(n=150)$ of internal medicine, $47 \%(n=27)$ of surgery, $54 \%(n=60)$ of traditional Chinese medicine and $52 \%(n=84)$ of other clinical types $(\mathrm{P}=.000)$.

${ }^{d}$ Men were more likely than women to provide online consultation ( $75 \%, n=590$ vs 
medRxiv preprint doi: https://doi.org/10.1101/2020.02.11.20022095; this version posted February 12, 2020. The copyright holder for this preprint (which was not certified by peer review) is the author/funder, who has granted medRxiv a license to display the preprint in perpetuity.

All rights reserved. No reuse allowed without permission.

$65 \%, n=631 ; P=.000$ ). 